American Journal of Pharmaceutical Education 2019; 83 (3) Article 7308.

\title{
COMMENTARY
}

\section{Practical Approaches to Integrate the Topic of Drug Shortages Within Doctor of Pharmacy Curricula}

\author{
Krisy-Ann Thornby, PharmD, ${ }^{a}$ Robert Thornby, PharmD, ${ }^{b}$ Carlos A. Torrado, PharmD, JD ${ }^{\mathrm{a}}$ \\ ${ }^{a}$ Gregory School of Pharmacy, Palm Beach Atlantic University, West Palm Beach, Florida \\ b Jupiter Medical Center, Jupiter, Florida
}

Submitted August 2, 2018; accepted November 19, 2018; published April 2019.

\begin{abstract}
Drug shortages have a significant impact on the health care system. As concerns grow over this topic, the health care community continues to explore strategies for reducing its impact on patient care. Exposure during the pharmacy curriculum will prepare students to engage and be at the forefront of this issue. Pharmacy educators should evaluate if opportunities exist to incorporate discussions or activities related to drug shortages. Integration of this content can occur throughout the curriculum as introductory or reinforcement topics in courses related to social/administrative/behavioral sciences, informatics, drug information, case studies, pharmacotherapy, law, and ethics. Applying this topic can be done during pharmacy practice experiences and interprofessional activities. Addressing this topic intentionally and developing strategies to promote optimal care in patients amid drug shortages begins with educating pharmacy students about this issue and developing their problem-solving skills.
\end{abstract}

Keywords: drug shortages, pharmacy education, pharmacists, curriculum, patient care

Drug shortages are a significant public health issue affecting the medication supply chain, health care providers, and patient care. Managing drug shortages has become an ongoing challenge and daily activity for practicing pharmacists. The Food and Drug Administration (FDA) defines a drug shortage as "a period of time when the demand or projected demand for a medically necessary drug in the United States exceeds its supply." "The FDA's definition may be limited in such that many drug shortages that affect patient care may not be classified as medically necessary. The American Society of HealthSystem Pharmacists (ASHP) considers a shortage once the product is in short supply as confirmed with manufacturers regardless of whether the drug is medically necessary or not. ${ }^{1}$ The Drug Information Service at University of Utah Health Care collaborates with ASHP to manage its drug shortage program and provide the public with updated national drug shortage statistics. The latest national data shows that there are 276 current active shortages in the first quarter of 2019 with 49 of these classified as new. ${ }^{2}$ Over half of the drug shortages reported were a result of unknown causes while the remaining reasons were manufacturing, supply and demand, discontinuation, natural disaster and lack of raw material. ${ }^{2}$ Due to

Corresponding Author: Krisy-Ann Thornby, Gregory

School of Pharmacy, Palm Beach Atlantic University, $901 \mathrm{~S}$. Flagler Dr., West Palm Beach, FL 33416-4708. Tel: 561-8032724. E-mail: Krisy_Thornby@pba.edu recent natural disasters and its impact on patient care, drug shortages have gained the attention of the public and the media. Despite this, shortages are a familiar territory for experienced pharmacists. In 2011, ASHP reported 267 new shortages, the highest to date. ${ }^{2}$ In response to this shortage, the Reducing Prescription Drug Shortages executive order was signed. ${ }^{3}$ In July 2018, the FDA formed a drug shortages taskforce to address the issue and seek solutions to lessen the underlying causes. ${ }^{4}$ Since then, a docket outlining the issue was drafted, a public meeting was held inviting all key stakeholders and comments were solicited for public comment until January 2019. The final report has not been released. ${ }^{4}$

As medication experts, pharmacists are at the helm of tasks necessary to solve the shortage issue. Examples of activities that are commonly performed by pharmacists when managing drug shortages are listed in Table 1. Kaakeh and colleagues evaluated the time spent managing drug shortages in 300 US hospitals. They found that in 2010, pharmacists spent nine hours per week managing drug shortages while physicians and nurses spent less than 30 minutes per week on the issue. ${ }^{5}$ Baumer and colleagues conducted a similar survey in 2004 and found that pharmacists spent approximately three hours. ${ }^{6}$ Caulder and colleagues' study, which aimed at identifying problems that occur as a result of drug shortages, received 219 responses from hospital pharmacy directors in the southeastern United States. ${ }^{7}$ They found that drug shortages produce a trickle effect potentiating medication errors at 


\section{American Journal of Pharmaceutical Education 2019; 83 (3) Article 7308.}

Table 1. Examples of Activities Performed by Pharmacists in Managing Drug Storages (Adapted from Baumer and colleagues) ${ }^{6}$

Tracking and researching the details about the shortage Identifying therapeutic alternatives

Purchasing therapeutic alternatives

Preparing written communications for health care providers

Providing in-service education to hospital staff

Updating electronic information systems

Contacting vendors/manufacturers/GPOs/wholesalers

Developing/modifying policies (eg, care plans, guidelines)

Compounding and packaging pharmaceuticals

a rate of $1 \%$ to $5 \%$ and may also cause negative clinical outcomes as a result of using compounded products or less ideal alternatives. Respondents reported that these drug shortages can lead to unsafe practices for both patients and staff $60 \%$ of the time, reaffirming the burden added to the complex health care delivery system. The authors concluded that "The profession should consider formally educating pharmacy students about drug shortages and global management strategies through their didactic curriculum." "7 This commentary will outline several concepts and steps that can be taken to carry out this recommendation and promote a more formal education training of managing drug shortages in the pharmacy curriculum.

\section{Drug Shortage Landscape in the Pharmacy Education Curriculum}

Pharmacy schools have comprehensive accreditation standards for curriculum development. Many of these standards indirectly address the conceptual framework one would need to respond to drug shortage inquiries as a more administrative skillset. The 2016 standards for the entry level Doctor of Pharmacy (PharmD) degree set forth by the Accreditation Council for Pharmacy Education (ACPE) discuss that pharmacy schools should develop future pharmacists with problem-solving abilities so that "The graduate is able to identify problems; explore and prioritize potential strategies; and design, implement, and evaluate a viable solution." " The complexity involved in managing drug shortages directs the students through each of these steps and can develop their problem-solving abilities. Appendix 1 of these standards provides the required elements for the didactic PharmD curriculum. These elements are intended to provide entry-level practitioners a firm foundation and prepare them to be "practice ready." The four major curriculum content areas include biomedical, pharmaceutical, social/administrative/behavioral and clinical sciences. While these standards provide guidance, they are not intended to be prescriptive and allow each school to develop their own program outcomes to adequately train students on concepts pharmacists should master. While the standards do not directly highlight drug shortage management, this contemporary topic fits in several sub-category areas listed within the social/behavioral/administrative or clinical sciences sections.

In 2014, the Joint Commission of Pharmacy Practitioners created the Pharmacists' Patient Care Process (PPCP) to depict the role of pharmacists in the delivery of patient care. ${ }^{9}$ This wheel-shaped approach is divided among five core sections revolving around patientcentered care. Among the five sections, the "assess" step describes the pharmacist's role in gathering patient information, prioritizing a patient's problem list and analyzing factors prior to selecting an optimal care plan. One of these factors states "....access to medications or other aspects of care." Students should recognize how lack of access to medications, because of drug shortages, can affect appropriate therapy selection. This will require them to use problem-solving skills to formulate alternative treatment recommendations tailored to patientspecific parameters.

In 2016, the American College of Clinical Pharmacy revised the curriculum toolkit for content taught in pharmacotherapy courses intended to assist pharmacy schools and colleges in developing, maintaining, and modifying their curriculum. ${ }^{10}$ It is specifically noted that "the toolkits permit flexibility to emphasize additional content areas for which schools have particular faculty expertise, adequate infrastructure, and specialized practice opportunities." ${ }^{10}$ Topics are categorized among three competency-based tiers according to the level of education and training provided. Tier one suggests that students receive formal education and training on various therapeutic topics prior to graduation and licensure, whereas tier two suggests that while students may be formally taught these topics, further training after graduation (eg, residency training) may be warranted to practice collaboratively and provide direct patient care. The third tier corresponds to topics that, while students or residents may not receive formalized training, they are expected to acquire the knowledge and skills as pharmacy practitioners. While the toolkit relates specifically to pharmacotherapy of disease states, common drug classes in short supply fall under all three tiers that could be tailored to the tier and content area taught, as appropriate.

With this issue affecting the vast health care delivery system, it is essential to involve other health care professionals. To promote interprofessional learning experiences and guide the curriculum development across professions, the Interprofessional Education Collaborative, comprised of six national health associations, joined 


\section{American Journal of Pharmaceutical Education 2019; 83 (3) Article 7308.}

together to form four core competency domains. ${ }^{11}$ The first domain involves developing an environment of mutual respect and shared values among the varied health professions. The second domain describes the acknowledgement of each health profession's roles and responsibilities to advance patient care. The third domain's core focus is interprofessional communication among patients, communities, and other health professionals. The fourth domain describes the application and use of team values and teamwork to effectively plan, deliver and evaluate patient and population-based care. As greater interaction occurs in health schools' didactic curriculum, this topic can ignite collaboration among providers for the optimal delivery of care amid shortages. Directors of interprofessional education (IPE) may discuss this topic in an IPE forum or a case-based problem to which each health professional group can contribute. The sixth edition of the textbook Drug Information: A Guide for Pharmacists includes a new chapter on drug shortages and provides examples of case study questions that can be incorporated into an IPE activity. ${ }^{12}$

After obtaining the PharmD degree, graduates are required to successfully pass the North American Pharmacist Licensure Examination (NAPLEX). The NAPLEX outline lists "emergency preparedness protocols" in one of the two major areas as an expected competency to prepare for the licensure examination prior to becoming a pharmacist. ${ }^{13}$ Despite this extensive guidance, the notion and extent by which drug shortages are threaded in the didactic curriculum may vary, be overlooked, or minimized to one particular course (eg, social and pharmacy administrative sciences) where this topic may have been implied to fit.

On a post-graduate level, the Board of Pharmacy Specialties (BPS) is a well-established post-licensure certification agency offering pharmacists specialty certifications in 13 practice areas of pharmacy. ${ }^{14}$ This certification can be achieved after completion of pharmacy didactic training plus one to two years of residency or three to four years of clinical practice experience, depending on the specialty. Each specialty provides a pharmacy examination content outline detailing specific domains, tasks and knowledge required to demonstrate competency in the respective practice area. Interestingly, six of the 13 BPS specialties which are cardiology, critical care, nutrition, oncology, pediatrics and pharmacotherapy, explicitly mention drug shortages as a knowledge area of importance. Examples of tasks listed are: "Principles of formulary development and management, including strategies for managing drug shortages; establish a plan to manage and communicate nutrition product shortages; management and conservation strategies related to drug shortages; facilitate access to care and treatment in times of crisis (eg, disaster, drug shortage); emergency preparedness and drug shortage resources."15-17

Knowledge and awareness of drug shortages in the aforementioned curricular threads should provide a basis of importance for drug shortage inclusion in the pharmacy curriculum. Key stakeholders such as directors of experiential education, interprofessional education faculty, pharmacy practice faculty and preceptors, should assess how students are exposed throughout the curriculum to the role of pharmacists in handling drug shortages and evaluate if this formalized training helps better equip students to apply the principles of the PPCP when presented with this ongoing challenge.

\section{Opportunities for Reinforcement in the Didactic Curriculum}

Schools' curriculum committees are natural venues to review how shortages are being addressed and identify if opportunities exist to incorporate these introductory lectures or activities. Courses related to the social, administrative and behavioral sciences are an obvious fit for integrating this content related to access, quality and distribution of medications in health care. In addition, pharmacy law courses can showcase the causal relationship between regulatory enforcement actions and their effect on the supply chain (eg, product shortage after a current good manufacturing practices (cGMP) violation), open discussions about gray market activities and their implications on patient safety, and discuss pharmacists' liability when substituting an unavailable product. Also, lack of availability on a lifesaving drug can make for a great discussion topic for ethics courses. Questions such as, who should the medication be reserved for and what criteria and exceptions may apply, can help students internalize how shortages affect their ability to care for the patient.

Drug information courses can introduce students to frequently consulted shortage resources. For example, the ASHP Guidelines on Managing Drug Product Shortages is a key resource for hospital pharmacists and should be recognized and used by students when presented with simulated case activities. ${ }^{18}$ Table 2 provides options that can be used in a problem-based scenario to reinforce and showcase the types of information that are available or in many cases, information that is considered unavailable to handle drug shortage requests. This activity can stimulate conversation and develop investigative skills to address the findings stated by Kaakeh and colleagues that "current information available to manage drug shortages is considered suboptimal."

Even if the topic of drug shortages has an allotted amount of time in the curriculum, reinforcement can 


\section{American Journal of Pharmaceutical Education 2019; 83 (3) Article 7308.}

Table 2. Opportunities for Drug Shortage Integration Throughout Pharmacy Curriculum

Introductory

Social/Administrative/Behavioral Science

Inventory system changes (eg, affiliation with other institutions, major and alternative group purchasing organizations, obtaining compounded replacement products)

Fiscal implications for pharmacy's budget from shortages and price gouging

Medication Errors

Adverse outcomes precipitated by shortages (eg, omission, dispensing error related to administration or dosing, procedure delays, altered length of stay, sentinel event)

Pharmacy Informatics

Pharmacist's role in medication decision support (eg, assessing changes needed to technology)

Drug Information

Drug Shortages Resources (eg, ASHP shortage website/mobile application/RSS feeds, FDA website, group purchasing organization's website, manufacturer's website, Institute for Safe Medication Practices newsletters, CDC website)

Reinforcement

Case Studies in Pharmacotherapy

Drug shortage themed case: identifying shortage, alternatives, follow up with other health professionals, and monitoring patients for adverse events

Pharmacotherapy

Integration of relevant and common critical medication classes affected by shortages (eg, electrolytes, antibiotics, chemotherapy, central nervous system, cardiovascular, opioids)

Pharmacy Law

Manufacturing process (cGMPs), government (eg, enforcement actions, policy changes, executive orders), substitution liability, Ethics recalls, mergers

Patient selection, gray/black market acquisition, corporate disclosure of impending shortage, treatment rationing, discontinuation of production

Application

Interprofessional education

Drug shortage education seminar or case-based problem scenario

Introductory and advanced pharmacy practice experiences

Portfolio requirement documenting drug shortage tasks (eg, student reflections, clinical intervention involving shortage, participation in action plan/computerized order set)

Counseling patients on drug shortages

occur in the pharmacotherapy sequences and problembased case study courses. Considering the breadth of content required in the pharmacotherapy sequence, it is understood that discussion of drug shortages is not likely or not an explicit learning outcome. However, the faculty's familiarity of the relevant drug classes with the highest rates of shortages may serve as a prime opportunity to interweave this contemporary topic and allow students to work through an appropriate strategy identifying the shortage and devising alternatives along with expected monitoring.

\section{Opportunities for Reinforcement in the Experiential Curriculum}

In the early stage of the curriculum, students participate in introductory pharmacy practice experiences
(IPPE). These rotations expose students to contemporary pharmacy practice. During these clerkships many students will gain familiarity with drug shortages, which ideally are further emphasized during advanced rotations. The advanced pharmacy practice experiences (APPE) "integrate, apply, reinforce, and advance the knowledge, skills, attitudes, abilities, and behaviors developed in the Pre-APPE curriculum and in co-curricular activities." 8 During these experiences, students will likely encounter drug shortage requests. Preceptors may involve students in several activities as listed in Table 1. Experiential departments may require students to directly highlight where they were involved in a drug shortage request in a rotation reflection or clinical intervention documentation. The mere cognition of performing this required task may place value on the issue and preemptively cause 


\section{American Journal of Pharmaceutical Education 2019; 83 (3) Article 7308.}

students and preceptors to seek meaningful tasks that are mutually beneficial. Another APPE may be involving students in advocacy at the state or national level during elective clerkships in pharmacy organizations or government agencies. Although these rotations may limit the number of students they are able to precept and may have a special application process, the experience may reflect a different perspective for students and increase interest and involvement with advocacy for the profession.

While on APPE rotations, students are expected to be team ready or "contribute as a member of an interprofessional collaborative patient care team." ${ }^{\text { As mentioned }}$ earlier, physicians and nursing colleagues will spend significantly less time on drug shortages than pharmacists, but will still bear much of the impact as a result. In a June 2018 report, the American Medical Association (AMA) Council on Science and Public Health referred to the drug shortage issue as an "urgent public crisis." 19 In this report, the AMA amended their National Drug Shortages policy, H-100.956, with several new recommendations, some of which include evaluating the impact of group purchasing organizations (GPO) on shortages, urging the FDA to provide greater transparency regarding causes of shortage and expected durations as well as production locations of drugs. The AMA also called for electronic health record (EHR) vendors to assess the ease of making drug shortage changes. Pharmacy organizations working alongside the AMA give greater recognition to the problem and accord for solutions.

\section{Recommendations and Potential Areas to Promote Awareness Among Future Pharmacists}

Our recommendations discussed here are intended to bring awareness to schools of pharmacy on the drug shortage problem and provide suggestions for content that could be threaded into the existing curriculum framework. The curriculum committee is often concerned when new content is being added and must weigh whether former material should be removed. The examples listed in Table 2 present opportunities for integration into current or relevant themes where the topic of drug shortages has a natural fit. While these examples may not all be used, incorporating this topic at various points in the curriculum can cover the different levels of learning within the cognitive domain and does not necessarily warrant additional time to coursework. The subject matter provided in Table 2 progresses hierarchically from introductory knowledge to reinforcement and application concepts. Although this topic may be tangentially introduced, the consistency across pharmacy schools and colleges is unknown and affected by a variety of factors like a school's location, clinical practice faculty experience with the issue, and time spent in the didactic curriculum and teaching methods. Addressing this topic intentionally and developing strategies to promote optimal care in patients amid drug shortages begins with pharmacy students' knowledge of the issue and development of their problem-solving skills. Pharmacy accreditation standards or other guiding documents such as ACCP's curriculum toolkit should consider the significance of the issue and discuss whether explicit language and formal training is warranted to prompt the attention of pharmacy schools. Increasing students' awareness may spur activism which can directly impact their experience during rotations, performance in residency programs, and ultimately as practitioners.

\section{REFERENCES}

1. The Food and Drug Administration Center for Drug Evaluation and Research. CDER Conversation: FDA's drug shortages prevention strategies. https://www.fda.gov/drugs/newsevents/ ucm432474.htm. Accessed October 26, 2018.

2. American Society of Health-System Pharmacists. Drug Shortages Statistics. National Drug Shortages: Annual New Shortages by Year. https://www.ashp.org/Drug-Shortages/Shortage-Resources/DrugShortages-Statistics. Accessed April 15, 2019.

3. U.S. Government Publishing Office. Executive Order 13588 of October 31, 2011. Reducing Prescription Drug Shortages. https:// www.gpo.gov/fdsys/pkg/CFR-2012-title3-vol1/pdf/CFR-2012title3-vol1-eo13588.pdf. Accessed October 26, 2018.

4. Food and Drug Administration. Statement by FDA Commissioner Scott Gottlieb, M.D. and Director of FDA's Center for Drug

Evaluation and Research Janet Woodcock. FDA is advancing new efforts to address drug shortages. https://www.fda.gov/NewsEvents/ Newsroom/FDAVoices/ucm626108.htmAccessed April 16, 2019.

5. Kaakeh R, Sweet B, Reilly C, et al. Impact of drug shortages on U.S. health systems. Am J Health Syst Pharm. 2011;68(19):18111819.

6. Baumer AM, Clark AM, Witmer DR, Geize SB, Vermeulen LC, Deffenbaugh JH. National survey of the impact of drug shortages in acute care hospitals. Am J Health Syst Pharm. 2004, 61(19):20152022.

7. Caulder CR, Mehta B, Bookstaver PB, et al. Impact of drug shortages on health system pharmacies in the Southeastern United States. Hosp Pharm. 2015;50(4):279-286.

8. Accreditation Council for Pharmacy Education. Accreditation standards and key elements for the professional program in pharmacy leading to the doctor of pharmacy degree. "Standards 2016."

Chicago, IL: ACPE. https://www.acpe-accredit.org/pdf/

Standards2016FINAL.pdf. Accessed October 26, 2018.

9. Joint Commission of Pharmacy Practitioners. The Pharmacists'

Patient Care Process. https://jcpp.net/patient-care-process/. Accessed October 26, 2018.

10. Schwinghammer TL, Crannage AJ, Boyce EG, et al. The 2016 ACCP Pharmacotherapy Didactic Curriculum Toolkit. Pharmacotherapy. 2016;36(11):e189-e194.

11. Interprofessional Education Collaborative. Core competencies for interprofessional collaborative practice: 2016 update. https://nebula. wsimg.com/2f68a39520b03336b41038c370497473?AccessKeyId= DC06780E69ED19E2B3A5\&disposition $=0$ \&alloworigin $=1$.

Accessed October 26, 2018. 


\section{American Journal of Pharmaceutical Education 2019; 83 (3) Article 7308.}

12. Fox ER. Drug Shortages and Counterfeit Drugs. In: Malone PM, Malone MJ, Park SK. eds. Drug Information: A Guide for Pharmacists, 6e New York, NY: McGraw-Hill. http://accesspharmacy. mhmedical.com/content.aspx ?bookid $=2275 \&$ sectionid $=177200029$. Accessed October 26, 2018.

13. National Association Boards of Pharmacy. North American Pharmacist Licensure Examination and Multistate Pharmacy Jurisprudence Examination. 2018 Candidate Application Bulletin. https://nabp.pharmacy/wp-content/uploads/2018/05/NAPLEXMPJE-Bulletin-May-14-2018.pdf. Accessed October 26, 2018. 14. Board of Pharmacy Specialties. https://www.bpsweb.org/bpsspecialties/\#1522337393496-965d3382-2121. Accessed April 16, 2019.

15. Board of Pharmacy Specialties. Cardiology Pharmacy Exam Content Outline. https://www.bpsweb.org/wp-content/uploads/ 2017CardioContentOutline.pdf. Accessed October 26, 2018.
16. Board of Pharmacy Specialties. Nutrition Support Pharmacy Exam Content Outline. https://www.bpsweb.org/wp-content/ uploads/2015/11/content_nutrition.pdf. Accessed October 26, 2018. 17. Board of Pharmacy Specialties. Pharmacotherapy Pharmacy Exam Content Outline. https://www.bpsweb.org/wp-content/ uploads/bps-specialties/pharmacotherapy/pharma_fall.pdf. Accessed October 26, 2018.

18. Fox ER, McLaughlin MM. ASHP guidelines on managing drug product shortages [published online ahead of print (July 30, 2018)]. Am J Health-Syst Pharm. 2018;75:e593-601. http://www.ajhp.org/ content/ajhp/early/2018/08/10/ajhp180441.full.pdf. Accessed October 26, 2018.

19. American Medical Association House of Delegates. Report of Reference Committee E. https://www.ama-assn.org/sites/default/ files/media-browser/public/hod/a18-ref-comm-e.pdf. Accessed October 26, 2018. 